\title{
Natural Remodeling of the Distal Anastomosis of an Above-Knee Femoropopliteal Bypass Depicted by CT Angiography of Lower Limbs Improves Geometry of the Reconstruction
}

\author{
G. GRUSOVA ${ }^{1}$, L. LAMBERT ${ }^{2}$, J. KAVAN ${ }^{2}$, A. LAMBERTOVA ${ }^{3}$, A. BURGETOVA ${ }^{2}$, \\ M. MLCEK ${ }^{4}$, T. GRUS ${ }^{5}$
}

${ }^{1}$ Fourth Department of Medicine, First Faculty of Medicine, Charles University and General University Hospital in Prague, Czech Republic, ${ }^{2}$ Department of Radiology, First Faculty of Medicine, Charles University and General University Hospital in Prague, Czech Republic, ${ }^{3}$ Department of Psychiatry, First Faculty of Medicine, Charles University and General University Hospital in Prague, Czech Republic, ${ }^{4}$ Institute of Physiology, First Faculty of Medicine, Charles University in Prague, Czech Republic, ${ }^{5}$ Second Department of Surgery, First Faculty of Medicine, Charles University and General University Hospital in Prague, Czech Republic

Received March 20, 2018

Accepted May 23, 2018

On-line September 11, 2018

\section{Summary}

The geometry of the distal anastomosis of a femoropopliteal bypass influences local hemodynamics and formation of intimal hyperplasia. We hypothesized that the distal anastomosis of an above-knee femoropopliteal bypass undergoes remodeling that results in displacement of the original course of the popliteal artery and change in the anastomosis angle. We identified 43 CT angiography examination with proximal femoropopliteal bypass and either a preserved contralateral popliteal artery or previous CTA before construction of the bypass for comparison. In these examinations, we measured the displacement distance and angle at the level of the distal anastomosis and compared these measurements with clinical and imaging data. The displacement distance was $8.8 \pm 4.9 \mathrm{~mm}(\mathrm{P}<0.0001)$ and the displacement angle was $-1^{\circ}\left(\mathrm{IQR}=44^{\circ}\right)$. The angle between the inflow and outflow artery was $153 \pm 16^{\circ}(P<0.0001)$. There was a negative association between the displacement angle and the angle between the bypass and the outflow artery $(r=-0.318, P=0.037)$. Patients with reversed venous grafts had a greater displacement of the anastomosis $(14.7 \pm 3.0 \mathrm{~mm})$ than patients with prosthetic grafts $(8.0 \pm 4.5 \mathrm{~mm}, \mathrm{P}=0.0011)$. We conclude that construction of a distal anastomosis of proximal femoropopliteal bypass results in displacement of the original course of the popliteal artery towards the bypass and this effect is more pronounced in reversed venous grafts.

\section{Key words}

Femoropopliteal bypass • Remodeling • Vascular anastomosis • Angle • Peripheral arterial disease

\section{Corresponding author}

L. Lambert, Department of Radiology, First Faculty of Medicine, Charles University and General University Hospital in Prague, U Nemocnice 2, 12808 Prague 2, Czech Republic. Fax: +420 224963048. E-mail: lambert.lukas@gmail.com

\section{Introduction}

Femoropopliteal bypass has been the most common procedure in vascular surgery performed in patients with peripheral arterial disease worldwide (Gerhard-Herman et al. 2017). The performance of the reconstruction has been vastly researched and numerous improvements targeting the geometry of the anastomosis, compliance mismatch between the graft and the target artery, and the graft itself have been introduced into practice. Although saphenous vein grafts have superior performance with primary patency rates about $77 \%$ at 5 years and should be preferred, they are not always available, and prosthetic grafts with a lower 5-year patency rates of $57 \%$ have to be used instead (Pereira et al. 2006). 
Formation of intimal hyperplasia in distal endto-side anastomosis of a femoropopliteal bypass has been described in numerous studies (Grus et al. 2009, McGah et al. 2012, Zilla et al. 2012). Intimal hyperplasia which is the main cause of graft failure within the first postoperative year is a complex phenomenon (Dolmatch et al. 2007). Disturbed hemodynamics in the anastomosis especially too low or high wall shear stress has been identified to promote its formation (Grus et al. 2009, Grus et al. 2016a, Subbotin 2007). Based on clinical and simulation studies, several improvements addressing hemodynamics, including construction of an acute anastomosis angle, have been proposed (Bellosta et al. 2013, Grus et al. 2016a, Grus et al. 2016b).

To our best knowledge, little research has been done to evaluate postoperative changes in the geometry of the distal anastomosis including the anastomosis angle and displacement of the anastomosis. In this study, we hypothesized that the distal anastomosis of an above-knee femoropopliteal bypass undergoes remodeling that results in displacement of the original course of the target artery and change in the anastomosis angle. To demonstrate this, we analyzed the geometry of the distal anastomosis on CT angiography of lower limbs (CTA) in patients with proximal femoropopliteal bypass.

\section{Material and Methods}

This retrospective analysis was performed in accordance with the Declaration of Helsinki, it was approved by the local Ethics Committee, and informed consent was waived.

From CTA examinations $(n=507)$ of lower limbs performed in a single center between January 2015 and August 2017, we identified 43 examinations with proximal femoropopliteal bypass and distal end-to-side anastomosis and either a preserved contralateral popliteal artery or previous CTA before construction of the bypass.

The examinations were performed on a 256-slice scanner (Brilliance iCT 256; Philips Healthcare, Best, The Netherlands) with peak tube voltage of $100 \mathrm{kV}$ as a breath-hold arterial phase acquisition triggered by bolus tracking in the abdominal aorta and reconstructed in $0.9 \mathrm{~mm}$ thin sections. Clinical data (including operation protocols) were retrieved from the hospital database.

In CTA examinations, a board-certified radiologist with experience in CTA evaluated 1) distance of the anastomosis from knee joint; 2) patency of the bypass, inflow and outflow artery; 3 ) angle between the

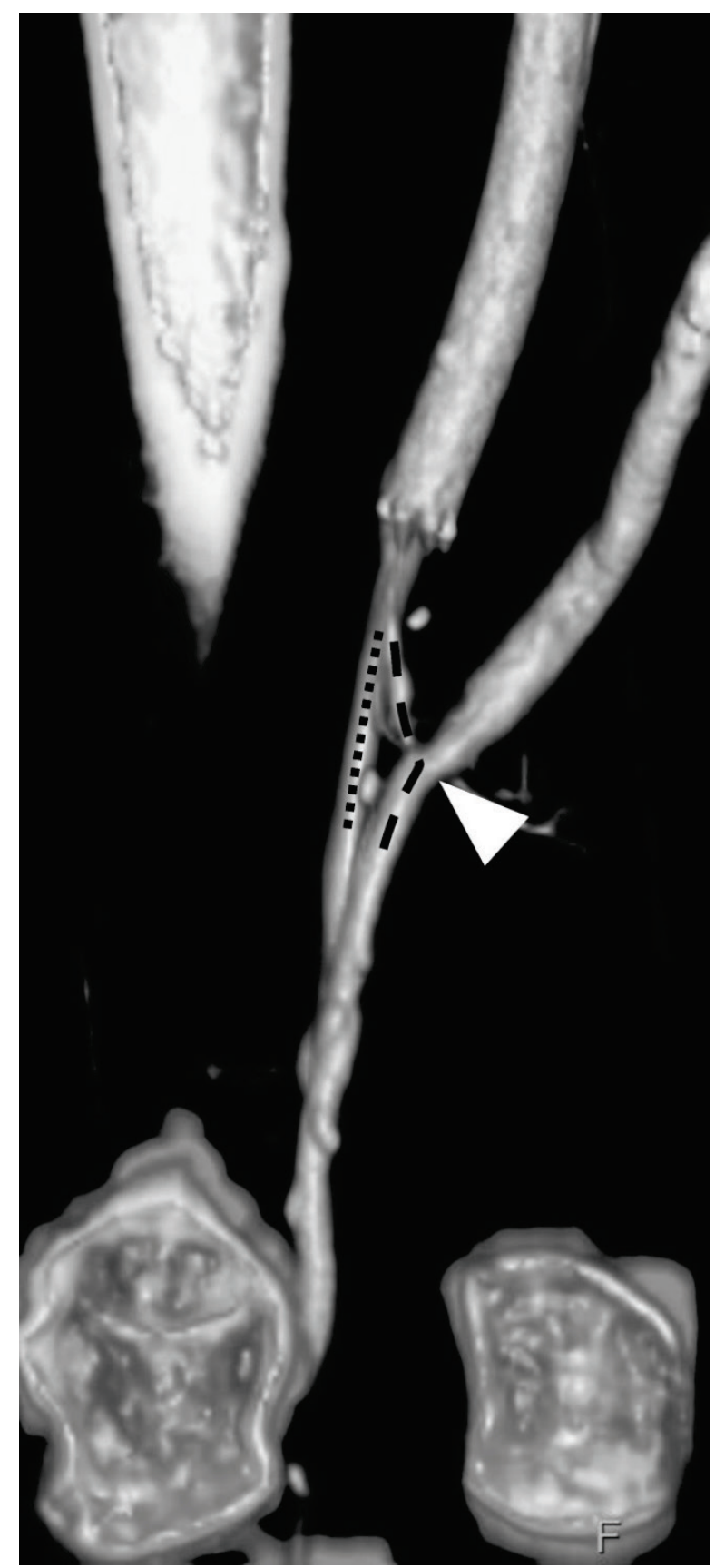

Fig. 1. Displacement of the popliteal artery (dashed line) at the level of the distal anastomosis (arrowhead) of an above-knee femoropopliteal bypass in a 68-year-old patient compared to the contralateral side (dotted line) on a fused CTA image.

bypass and the outflow artery; 4) angle between the inflow and the outflow artery; 5) displacement distance and angle at the level of the anastomosis. The displacement distance was measured in axial plane as the distance between the floor of the distal anastomosis and the popliteal artery on the contralateral side on the same CTA $(n=40)$ or on the ipsilateral side on previous CTA $(n=3)$ after fusion of the two images based on similarity of anatomical structures (Fig. 1). The displacement angle was measured as the 
angle between the displacement line and horizontal line. In one-third of the sample $(n=11)$ the displacement angle, distance and the angle between the bypass and the outflow angle were re-measured to assess intraobserver agreement. The evaluation and measurements were performed on a clinical workstation (Intellispace Portal, Philips Healthcare, Best, The Netherlands).

Statistical evaluation was performed in Prism 5.0 (GraphPad Software, San Diego, USA). The normality of the data was tested using the D'Agostino-Pearson omnibus test. To test the significance of the displacement distance or the angle between the inflow and outflow segment the t-test was used. The relationship between the displacement distance or angle and other parameters was expressed using Pearson's correlation coefficient (r) for continuous variables. Binary variables were compared using the t-test. The intraobserver agreement was expressed as Pearson's correlation coefficient (r). A P value below 0.05 was considered significant.

\section{Results}

The patients were $68 \pm 7$ years old and $38(88 \%)$ were males (Table 1). The time between the operation and $\mathrm{CT}$ was 52 (interquartile range $[\mathrm{IQR}]=76$ ) months and 35 patients $(81 \%)$ had a PTFE (polytetrafluorethylene) graft with an internal diameter from 6 to $8 \mathrm{~mm}$ (Table 2). Occlusion of the bypass was noted in 13 (30\%) patients. Inflow and outflow artery was stenosed or occluded in 40 (93\%) and 11 (26\%), respectively.

The displacement distance of the anastomosis was $8.8 \pm 4.9 \mathrm{~mm}(\mathrm{P}<0.0001)$ and the displacement angle was $-1^{\circ}\left(\mathrm{IQR}=44^{\circ}\right.$, Table 3, Fig. 2). The angle between the inflow and outflow artery was $153 \pm 16^{\circ}(\mathrm{P}<0.0001)$. There was a negative association between the displacement angle and the angle between the bypass and the outflow artery $(\mathrm{r}=-0.318, \mathrm{P}=0.037)$. The correlation between the anastomosis angle $\left(153 \pm 16^{\circ}\right)$ and the distance of the anastomosis from the knee joint space (103 mm, IQR=21 mm) was weak $(\mathrm{r}=0.25, \mathrm{P}=0.11$, Table 4). Patients with reversed venous saphenous grafts had displacement of the anastomosis $(14.7 \pm 3.0 \mathrm{~mm})$ greater than patients with prosthetic grafts $(8.0 \pm 4.5 \mathrm{~mm}$, $\mathrm{P}=0.0011$ ). There was no significant difference in the displacement with regard to the gender, smoker status, or occlusion of the inflow artery or the bypass. The intraobserver agreement for the displacement angle, displacement distance, and the angle between the bypass and the outflow artery was $0.79,0.80$, and 0.94, respectively.
Table 1. Patients' characteristics.

\begin{tabular}{lc}
\hline Characteristics & $\mathrm{n}=43$ \\
\hline Gender (male) & $38(88 \%)$ \\
Age (years) & $68.4 \pm 6.7$ \\
Coronary artery disease & $20(47 \%)$ \\
Myocardial infarction & $9(21 \%)$ \\
Atrial fibrillation & $2(5 \%)$ \\
Diabetes & $23(53 \%)$ \\
Hypertension & $39(91 \%)$ \\
Hyperlipidemia & $32(74 \%)$ \\
Smoker or ex-smoker & $38(88 \%)$ \\
Body mass index $\left(k^{2} / m^{2}\right)$ & $28.7 \pm 4.6$ \\
Fontaine classification before the bypass \\
IIB \\
III & $18(42 \%)$ \\
IV & $14(33 \%)$ \\
\hline
\end{tabular}

Table 2. Bypass types.

\begin{tabular}{lc}
\hline Characteristics & $\mathrm{n}=43$ \\
\hline Bypass type & \\
PTFE & $35(81 \%)$ \\
Reverse VSM & $6(14 \%)$ \\
In-situ VSM & $2(5 \%)$ \\
Side (right) & $21(49 \%)$ \\
PTFE diameter $(\mathrm{mm})$ & $7.2 \pm 0.6$ \\
\hline
\end{tabular}

PTFE, polytetrafluoroethylene graft; VSM, v. saphena magna.

Table 3. Data determined or measured from CT angiography of lower limbs.

\begin{tabular}{lc}
\hline Characteristics & $\mathrm{n}=43$ \\
\hline $\begin{array}{l}\text { Distance from knee (mm) } \\
\text { Patency }\end{array}$ & $103(\mathrm{IQR}=21)^{1}$ \\
Bypass (occluded) & $13(30 \%)$ \\
$\begin{array}{l}\text { Inflow (stenosed or occluded) } \\
\text { Outflow (stenosed or occluded) }\end{array}$ & $40(93 \%)$ \\
Geometry & $11(26 \%)$ \\
Angle between bypass and & $153 \pm 16$ \\
outflow artery (degrees) & \\
Angle between inflow and outflow & $143 \pm 18$ \\
$\begin{array}{l}\text { artery (degrees) } \\
\text { Displacement distance (mm) } \\
\text { Displacement angle (degrees) }\end{array}$ & $8.8 \pm 4.9$ \\
\hline
\end{tabular}

${ }^{1}$ Parameters with non-normal distribution are expressed as median and interquartile range (IQR). 
Table 4. Correlation of displacement distance and displacement angle with patient characteristics and data determined from $\mathrm{CT}$ angiography of lower limbs.

\begin{tabular}{|c|c|c|c|c|c|c|}
\hline & \multicolumn{3}{|c|}{ Displacement distance } & \multicolumn{3}{|c|}{ Displacement angle } \\
\hline & Pearson & $95 \%$ CI & $\mathbf{P}$ & Pearson & $95 \%$ CI & $\mathbf{P}$ \\
\hline Age & 0.215 & -0.092 to 0.484 & 0.17 & -0.039 & -0.336 to 0.264 & 0.80 \\
\hline Patient height & -0.089 & -0.379 to 0.218 & 0.57 & -0.011 & -0.310 to 0.291 & 0.95 \\
\hline$B M I$ & -0.033 & -0.331 to 0.270 & 0.83 & -0.041 & -0.338 to 0.262 & 0.79 \\
\hline Diameter of PTFE & 0.026 & -0.305 to 0.352 & 0.88 & -0.035 & -0.360 to 0.297 & 0.84 \\
\hline Distance from knee & 0.080 & -0.225 to 0.372 & 0.61 & 0.172 & -0.136 to 0.449 & 0.27 \\
\hline $\begin{array}{l}\text { Time between operation } \\
\text { and } C T\end{array}$ & 0.040 & -0.264 to 0.336 & 0.80 & -0.241 & -0.505 to 0.064 & 0.12 \\
\hline $\begin{array}{l}\text { Angle between bypass and } \\
\text { outflow artery }\end{array}$ & -0.0165 & -0.315 to 0.285 & 0.92 & -0.318 & -0.565 to -0.020 & 0.037 \\
\hline $\begin{array}{l}\text { Angle between inflow and } \\
\text { outflow artery }\end{array}$ & -0.099 & -0.388 to 0.207 & 0.53 & 0.136 & -0.171 to 0.420 & 0.38 \\
\hline
\end{tabular}

PTFE, polytetrafluoroethylene graft.
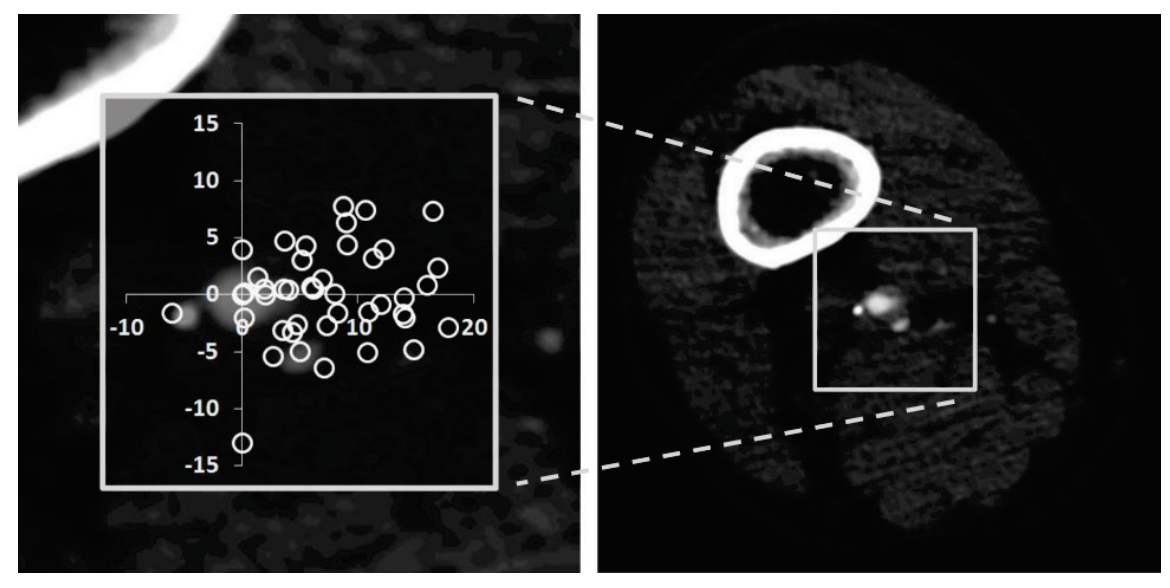

Fig. 2. Displacement of the popliteal artery after a median of 52 (IQR $=76$, $\mathrm{n}=43$ ) months after the bypass procedure shown on CT angiography of lower limbs. Compared to the contralateral side or previous examination, the distal popliteal artery at the level of the distal anastomosis of a femoropopliteal bypass shifted medially in most patients.

\section{Discussion}

This study demonstrated that construction of a distal anastomosis of proximal femoropopliteal bypass results in displacement of the original course of the popliteal artery towards the bypass and this effect is more pronounced in reversed venous grafts. The anastomosis angle correlates with the angle of this displacement.

Vascular grafts shall not be sutured under tension in order to minimize the risk of formation of a pseudoaneurysm at the anastomosis, dehiscence of the suture with hemorrhage, or early occlusion (Deery and Guzman 2018, Feliciano 2017, Handa and Sharma 2014). The length of the graft is trimmed precisely so that its distal end can be easily attached to the intended spot on the target (popliteal) artery without changing its course. Both PTFE and reverse venous grafts are tunelized without being firmly affixed to the surrounding connective tissue (Mills et al. 2016). The target segment of the popliteal artery is released from the adjacent tissue in the length of about $2-3 \mathrm{~cm}$. Because we found no correlation between the bypass age and displacement of the anastomosis, we believe that the displacement occurs in the early postoperative period.

We suggest that two mechanisms may mutually be responsible - healing of the surgical wound in the phase of proliferation with remodeling that occurs in the first postoperative months and hemodynamic pressure changes in the reconstruction (Diegelmann and Evans 2004, Reinke and Sorg 2012, Young and McNaught 2011). These assumptions are supported by the fact that the displacement in PTFE grafts was less pronounced compared to reverse venous grafts. Compared to venous grafts, PTFE grafts have negligible axial distensibility 
which results in decreased amplitude and propagation of pulse wave decreasing the hemodynamic force exerted on the anastomosis by flow directed through the graft (Sarkar et al. 2006). On the other hand, saphenous grafts can dilate both in the axial and longitudinal axis (Zilla et al. 2012).

Prosthetic grafts used for peripheral arterial revascularization are made of artificial material and their mechanical and biological properties can be modified. While low porosity of the graft discourages the formation of endothelial lining that results in reduced antithrombogenicity, high porosity promotes fibrovascular infiltration further reducing the compliance of the graft (Sarkar et al. 2006). Prosthetic grafts with a layered wall structure incorporate favorable properties of both designs, increase compliance of the graft, transmission of a pulse wave, and at the same time decrease thrombogenicity by adjusting porosity of the inner layer (Grus et al. 2018). In this respect, the use of biomaterials including bovine or freshwater fish collagen shows promising early results even in a low-flow setting (Chlupáč et al. 2009, Grus et al. 2018).

The natural remodeling of the anastomosis decreases the anastomosis angle and therefore improves hemodynamics in the reconstruction, promotes laminar flow and improves hemodynamic parameters known to induce neointimal hyperplasia (Grus et al. 2009, Grus et al. 2016a, Grus et al. 2016b).

In conclusion, this study showed the phenomenon of remodeling of the distal anastomosis of above-knee femoropopliteal bypass with regards to its displacement towards the bypass that results in angulation of the popliteal artery thus decreasing the anastomosis angle. The displacement of the original course of the popliteal artery towards the bypass is more pronounced in reversed venous grafts.

This study has several limitations. Firstly, the proportion of patients with saphenous graft was small. Secondly, there is a natural variability between the ipsilateral and contralateral leg in the soft tissue structures (especially muscles), which is also affected by the surgical procedure. Thirdly, mild variation in the tissue layout can be expected due to the positioning of the legs during the CTA. Fourthly, due to retrospective nature of this study, we were unable to comment on the variability among vascular surgeons.

\section{Conflict of Interest}

There is no conflict of interest.

\section{Acknowledgements}

This work was supported by Ministry of Health of the Czech Republic (grant nr. 15-27941A) and by the Charles University in Prague (Progres Q28/LF1, UNCE 204065).

\section{References}

BELlOSTA R, NATALINI G, LUZZANI L, CARUGATI C, SARCINA A: Comparison of precuffed expanded polytetrafluorothylene and heparin-bonded polytetrafluorothylene graft in crural bypass. Ann Vasc Surg 27 : 218-224, 2013.

CHLUPÁČ J, FILOVÁ E, BAČÁKOVÁ L: Blood vessel replacement: 50 years of development and tissue engineering paradigms in vascular surgery. Physiol Res 58 (Suppl 2): S119-S139, 2009.

DEERY SE, GUZMAN RJ: Anastomotic aneurysms. In: Rutherfords Vascular Surgery. JL CRONENWETT, KW JOHNSTON (eds), Elsevier Health Sciences, Philadelphia, 2014.

DIEGELMANN RF, EVANS MC: Wound healing: an overview of acute, fibrotic and delayed healing. Front Biosci 9: 283-289, 2004.

DOLMATCH B, DONG Y-H, HEETER Z: Evaluation of three polytetrafluoroethylene stent-grafts in a model of neointimal hyperplasia. J Vasc Interv Radiol 18: 527-534, 2007.

FELICIANO DV: Pitfalls in the management of peripheral vascular injuries. Trauma Surg Acute Care Open 2: e000110, 2017.

GERHARD-HERMAN MD, GORNIK HL, BARRETT C, BARSHES NR, CORRIERE MA, DRACHMAN DE, FLEISHER LA, FLOWKES FGR, HAMBURG NM, KINLAY S, LOOKSTEIN R, MISRA S, MUREEBE L, OLIN JW, PATEL RAG, REGENSTEINER JG, SCHANZER A, SHISHEHBOR MH, STEWART KJ, TREAT-JACOBSON D, WALSH ME, HALPERIN JL: 2016 AHA/ACC guideline on the management of patients with lower extremity peripheral artery disease. Circulation 135: e726-e779, 2017. 
GRUS T, LINDNER J, VIDIM T, TOSOVSKY J, MATECHA J, ROHN V, LAMBERT L, GRUSOVA G: The anastomosis angle is a key to improved long-term patency of proximal femoropopliteal bypass. Ann Vasc Surg 23: 598-605, 2009.

GRUS T, GRUSOVA G, LAMBERT L, BANERJEE R, MATECHA J, MLCEK M: The influence of the anastomosis angle on the hemodynamics in the distal anastomosis in the infrainguinal bypass: an in vitro study. Physiol Res 65: 591-595, 2016a.

GRUS T, LAMBERT L, MATĚCHA J, GRUSOVÁ G, ŠPAČEK M, MLČEK M: The ratio of diameters between the target artery and the bypass modifies hemodynamic parameters related to intimal hyperplasia in the distal endto-side anastomosis. Physiol Res 65: 901-908, 2016 b.

GRUS T, LAMBERT L, MLCEK M, CHLUP H, HONSOVA E, SPACEK M, BURGETOVA A, LINDNER J: In vivo evaluation of short-term performance of new three-layer collagen-based vascular graft designed for low-flow peripheral vascular reconstructions. BioMed Res Int 2018: Article ID 3519596, 2018.

HANDA R, SHARMA S: Vascular graft failure of leg arterial bypasses - a review. J Hypertens Cardiol 1: 17-21, 2014.

MCGAH PM, LEOTTA DF, BEACH KW, ZIERLER RE, RILEY JJ, ALISEDA A: Hemodynamic conditions in a failing peripheral artery bypass graft. J Vasc Surg 56: 403-409, 2012.

MILLS JL, HINCHLIFFE RJ, TRINIDAD-HERNANDEZ M: Technical aspects of infra-inguinal revascularization for chronic lower limb ischaemia. In: Oxford Textbook of Vascular Surgery. MM THOMPSON (ed), Oxford University Press, 2016, pp 278-291.

PEREIRA CE, ALBERS M, ROMITI M, BROCHADO-NETO FC, PEREIRA CAB: Meta-analysis of femoropopliteal bypass grafts for lower extremity arterial insufficiency. J Vasc Surg 44: 510-517, 2006.

REINKE JM, SORG H: Wound repair and regeneration. Eur Surg Res 49: 35-43, 2012.

SARKAR S, SALACINSKI HJ, HAMILTON G, SEIFALIAN AM: The mechanical properties of infrainguinal vascular bypass grafts: their role in influencing patency. Eur J Vasc Endovasc Surg 31: 627-636, 2006.

SUBBOTIN VM: Analysis of arterial intimal hyperplasia: review and hypothesis. Theor Biol Med Model 4: $41,2007$.

YOUNG A, MCNAUGHT C-E: The physiology of wound healing. Surg (Oxford) 29: 475-479, 2011.

ZILLA P, MOODLEY L, SCHERMAN J, KRYNAUW H, KORTSMIT J, HUMAN P, WOLF MF, FRANZ T: Remodeling leads to distinctly more intimal hyperplasia in coronary than in infrainguinal vein grafts. $J$ Vasc Surg 55: 1734-1741, 2012. 